\title{
Working from the Same Page: Collaboratively Developing Students' Research Skills Across the University
}

\begin{abstract}
Teaching and learning agendas in higher education spanning the past two decades have increased attention to the importance of learning strategies that equip undergraduate students with critical research skills required for successful study outcomes (Healey and Jenkins 2009). The literature extensively explores which research-led teaching methods, activities, and experiences develop students' research skills (Wilson, Howitt, Higgins 2015). However, strategies for explicitly incorporating research skills into curricula still remain largely unclear, aspirational, and difficult to realize as an institutionally driven educational strategy. This article describes a highly effective library-faculty partnership model for embedding research skills within disciplinary content, led by the Monash University Library, which has achieved broad impact across the institution. Since 2009, teams of librarians, learning-skills advisers, and faculty have been collaboratively implementing the Research Skill Development (RSD) framework (Willison and O'Regan 2006/2013) as an innovative learning and teaching initiative to embed and assess students' research skills within disciplinary contexts. The RSD framework articulates explicit, cyclical, and incremental development of students' research skills coherently in the curriculum.
\end{abstract}

The library-led grassroots initiative to implement the Research Skill Development (RSD) framework has achieved broad impact across Monash University in Australia. The RSD is providing a common language to catalyze library-faculty teaching partnerships in a variety of disciplines, focused on shared development of students' research skills. Library teams have successfully initiated partnerships with faculty and curriculum developers and recently with educational designers to catalyze RSD learning approaches across the university. Testifying to the success of the model, use of the RSD became a university-wide strategic priority in 2011 and the "backbone" of Monash University's education plans.

RSD-informed curricular and co-curricular activities engaged 118,558 students between February 2012 and June 2015 from all ten faculties at Monash University. The collaborative RSD model is now firmly established and key to guiding curriculum and assessment design that clearly informs development of students' research skills. The approach may be informative for other universities seeking to leverage collaborative strategies to enhance development of students' research skills through coursework.

\section{Background}

Over the past two decades, academic libraries worldwide have aimed to move from being service providers to becoming educational contributors, more clearly and actively connecting library expertise to students' learning within curricula (Smith 2011; Moselen and Wang 2014). Common approaches have relied on persuading faculty to enter into teaching partnerships with library staff members, in order to better connect information-literacy skills with disciplinary content (Bruce 2001; Kempcke 2002; Ivey 2003; Christiansen, Stombler, and Thaxton 2004; Weetman 2005). Information literacy includes a range of skills necessary for research proficiency, which can be defined as thinking and process skills that encompass the ability to: conceptualize, locate, interpret, evaluate, organize, synthesize, and communicate information (Bundy 2004).

Yet in spite of the efforts to foster teaching partnerships, the ability to communicate the academic library's potential contributions within the institution often remains lost in translation and largely aspirational (McGuinness 2006). As affirmed in the literature, this results in library expertise lingering outside and adjunct to the academic curriculum (Kempcke 2002; Christiansen, Stombler and Thaxton 2004; Chanock 2007; Wijayasundara 2008; Chen and Pei-Chun 2011). Current research by Hensley et al. showed that little has changed; library involvement in undergraduate research programs remains "overwhelmingly absent" and library engagement in curricula continues to be described as "anecdotes and case studies" $(2014,424)$. This suggests that libraries can rarely leverage curriculum change to embed research skills. The limitations often hindering the involvement of libraries in higher education curricula arise from traditional perceptions of information literacy as "locating information during course-related instruction" (Hensley et al. 2014, 423). A focus on locating information or on bibliographic instruction suggests a narrow interpretation of information literacy as search skills rather than skills for research.

This raises very important questions about strategic ap- 
proaches, organizational structures, and the elements required to enable effective, sustainable, and transferable programs that utilize academic library expertise to enhance students' research ability. Stamatoplos (2009) highlighted the need for change, suggesting that traditional library outreach strategies and teaching models require reconceptualization. He recommended a more sustainable model of library-faculty teaching collaboration that goes beyond discrete episodes of engagement.

\section{Background of the RSD Framework}

The RSD is a concise, conceptual framework that brings together multiple educational understandings of critical skills students require for research that are relevant to and underpin any curriculum and disciplinary context (Willison and O'Regan 2007; Willison and Buisman-Pijlman 2016). The cyclical and incremental development of students' research skills is articulated through a constructivist learning approach and incorporates student autonomy (Boud 1988), Australian and New Zealand Information Literacy standards (Bundy 2004), and Bloom and colleagues' Taxonomy of Educational Objectives (1956).

The RSD framework presents two axes. The vertical axis describes the research process as skills that encompass conceptualizing; clarifying and posing researchable questions; finding and generating information or data; evaluating, reflecting upon, and critiquing research methods, source credibility, and arguments; organizing and managing information; analyzing generated data and synthesizing information; applying knowledge and communicating understandings with an awareness of ethical and social issues throughout the research process.

The horizontal axis of the RSD framework relates to the extent of students' autonomy- "the conceptual space that students are given or experience when using the skills associated with research" (Willison, Sabir and Thomas, forthcoming) and the students' ability to undertake various aspects of the research process. This axis provides descriptors for designing incremental and progressively scaffolded research activities at the course or program level, a means to enable or operationalize and integrate undergraduate research skills seamlessly in the curriculum. Descriptions of student autonomy range from a closed research inquiry (low autonomy) requiring a focused research question and highly structured directions and modelling from the educator, to open research (high autonomy) where students initiate and determine the guidelines for their own research.

Therefore, the RSD framework not only describes what skills are associated with the research process, but also presents a conceptual model of how these skills can be progressively and coherently taught and demonstrated in the curriculum. The Research Skill Development framework is available at http://www.adelaide.edu.au/rsd/.

While on first impression these axes may appear rigid, suggesting a linear progression for both the research process and development of student autonomy, applications of the RSD framework across disciplines at Monash University have effectively demonstrated its ability to comprehensibly describe the entire research journey in a non-prescriptive, flexible, and adaptable manner. Within the framework, students may exhibit varying levels of autonomy for the different research skills or facets articulated, and they may oscillate between research facets during the process of research.

Further, a student's level of autonomy for a particular research skill set can cycle backward when faced with less familiar research tasks. As explained by Willison, Sabir and Thomas (forthcoming, 2), "This does not mean going backwards educationally, but rather provides insight into what happens in more conceptually demanding contexts." This flexibility is indicated by cyclical arrows projected along each axis of the framework, to capture the cyclical nature of research and research skill development.

\section{Monash Library's Evolving Contributions}

In contrast to current library models, in 2007 the Monash University Library refocused its interpretation and approach to teaching information literacy by establishing a new organizational teaching structure to extend the library's educational contribution to curricula. In this new model, learning-skills advisers are employed by the library to work in collaborative partnerships with librarians in dedicated disciplinary teams. These learning skills advisers bring curriculum expertise, teaching experience, and knowledge in developing student academic skills such as critical thinking, academic language, and communication skills (Smith 2011). Their expertise marries well with the information-literacy skills of academic librarians, thus expanding the library's contribution to developing students as researchers.

Hensley et al. have noted that library instruction rarely includes "topics related to scholarly communication, such as copyright, and research ethics" $(2014,434)$ and "developing critical thinking skills addressing the undergraduate student's role as author" (Hensley et al. 2014, 423). The blend of the expertise of librarians and learning-skills advisers, however, addresses all of these essential components of undergraduate research. Blending two distinct professional groups into cohesive and functional library teams required analytical discourse to find common ground, build trust, and demystify perceptions of each other's roles to enable collaboration.

To enable collaborative teaching practice between librarians and learning-skills advisers, the teaching teams adopted the RSD framework to underpin their teaching practice. Through collaborative RSD conversations, library teams 
have been able to interpret each other's roles, and explore the similarities, differences, and synergies of research-skill development from different professional perspectives. To more clearly communicate the educational and collaborative identity of librarians and learning-skills advisers, Monash University Library shifted from the traditional library nomenclature of "information literacy skills" to "research and learning skills." The intention was to remove any remedial misunderstandings associated with the term "literacy" and to communicate the library's holistic approach to developing a range of research and academic skills required for success at the university (Smith 2011). As a result, the library is better able to communicate and connect its expertise with faculty members and become more actively involved and valued for its ability to contribute to and influence pedagogy and curriculum design.

\section{The Library-Faculty Partnership Model}

In exploring ways to develop students as researchers, Jenkins and Healey $(2015,31)$ offer practical and achievable strategies that can be adapted by faculty to incorporate undergraduate research and inquiry into their teaching. The experience we share here is inclusive of the strategies espoused by Jenkins and Healey $(2015,31)$ enabled through an informal community of practice (Wenger 1988) and connected by the RSD framework. This community of practice $(\mathrm{CoP})$ will thus be referred to as the RSD CoP.

Collaborative learning is key to this relationship, in which the RSD CoP is not only a community of practice, but also a mixed community of interprofessional learners (librarians, learning skills advisers, and faculty) exploring how best to help students develop research skills, in the context of a discipline and in alignment with a curriculum. As Schrage explains, "collaboration is the process of shared creation: two or more individuals with complementary skills interacting to create a shared understanding that none had previously possessed or could have come to on their own" $(1990,40)$. In this shared space the RSD is the focal point that has fundamentally transformed the dynamics and the interaction among educators (Figure 1).

The RSD CoP provides a safe and nonthreatening learning environment in which approaches to applying the RSD in the curriculum can be explored and former hierarchical barriers can be overcome. Peers become partners in the shared learning space, understanding the "professional, pedagogic and discipline-based perspectives of each other's practice" (Torres, McCann, Croy, Mason and Schapper 2011). The outcomes are a deep understanding of the complementary skills library-faculty partners contribute to a curriculum, as well as scaffolded and explicit curricula to teach research skills.

The RSD CoP has steadily disseminated the use of the RSD framework to identify, develop, and explicitly assess students' research skills across curricula in all faculties. Ultimately, the RSD has been incorporated as a strategic educational priority and endorsed in the Monash University's Better Teaching Better Learning Agenda:

The development of a portfolio of skills should be at the heart of all modern educational offerings and Monash is well placed to implement a strong skills focus into all of its courses and units. Under the leadership of the library we have already adopted the Research Skill Development (RSD) framework from the University of Adelaide. We aim to use this ... to embed into the curriculum and become the backbone of the educational excellence experience. (Office of the ViceProvost, Learning and Teaching, Monash University 2013, 13)

The way in which the RSD has been institutionally endorsed has been sensitive and respectful of faculty and library staff and the journey they have travelled in reconceptualizing their practice. Importantly, the successful dissemination methods deployed by the library for the RSD, including the community of practice, demonstrated that this was a sustainable model. University policy therefore validated and supported but did not mandate RSD implementation. Faculty members adopted the RSD when the time was right for them, usually instigated by coursework-accreditation processes, curriculum review and renewal, course enhancement, and educational agendas focusing on developing students as researchers.

\section{Building Staff Capacity}

To disseminate the RSD framework and encourage its adoption across Monash, library teams developed and facilitated numerous RSD workshops. These workshops became known as "RSD Bring a Friend" (BaF) Workshops, to which librarians and learning skills advisers invite an academic "friend" to experience the RSD as a collaborative partnership approach.

\section{Figure 1. The RSD CoP Partnership Model.}

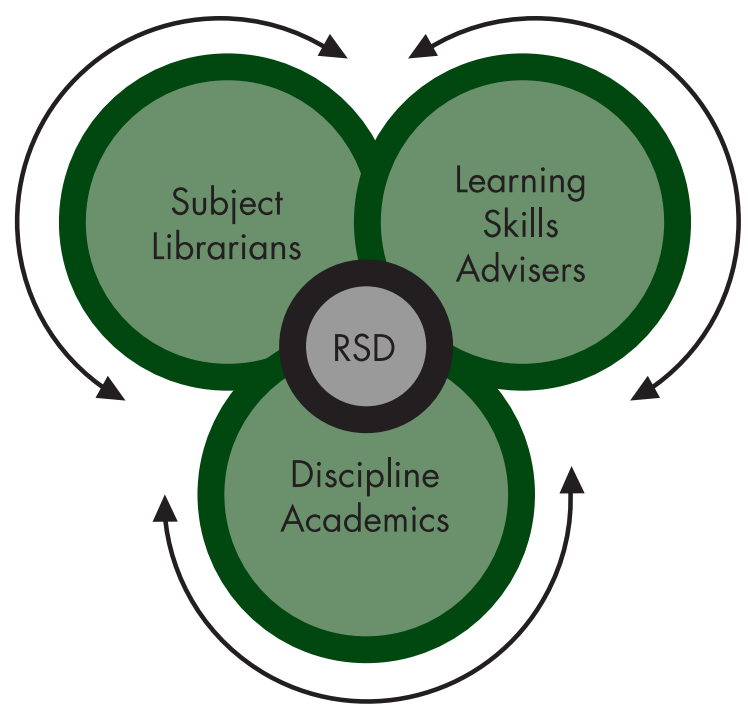


The RSD workshops are also a means to induct new library staff members into RSD teaching-and-learning applications, in keeping with "novice to expert" capacity-building strategies in which like-minded colleagues learn to collaboratively develop RSD teaching approaches in a community of practice (Lave and Wenger 1991).

For example, successful workshops delivered by the library for faculty titled "Improving Student Learning Outcomes with the RSD" have become part of a module in the curriculum of the graduate certificate of academic practice (GCAP) for early- and mid-career academics and newly appointed academic staff. The aim is to provide educators at Monash with opportunities to focus on issues relevant to their teaching contexts and disciplines. The module on the RSD unpacks the framework through discovery learning to facilitate revised conceptions of how to develop students' research skills. The workshop is designed to demonstrate how collaborative partnerships among educators can allow them to work "from the same page" to enhance student-learning outcomes.

The workshops are focused on practical outcomes, such as applying the RSD to design of assessment, in particular the development of RSD-informed marking rubrics that include the assessment of research skills. Opportunities are provided to interpret the RSD framework for an individual academic's context, and participants are assessed on their successful application of the RSD framework to one of their teaching units.

Feedback indicates that this module challenges thinking, particularly reflection on current approaches to curriculum design and assessment. Feedback also highlights how the RSD framework was found to be useful to identify what is required for skill development and to align assessment with marking criteria. By demonstrating the library's capacity to collaborate with faculty and contribute to teaching and learning agendas using the RSD, teaching partnerships are often formed that result in continued collaboration after the module's completion so as to further incorporate research skills as an explicit element in a curriculum.

Shared learning experiences that engage library staff and faculty with the RSD framework have highlighted the critical importance of having a tool to enable the articulation of students' research skills through a mutually understood language. As a result of the workshops and dissemination strategies aimed at building staff capacity, the library is now using the RSD to structure conversations with faculty around the requisite skills students need to effectively engage with coursework, the perception of students' skill levels, and the level at which they would like students to perform. This allows determination of which skills most need development. Professional partnerships guided and reconceptualized by the RSD framework incorporate planning, teaching, and evaluation, as well as the development of the partnership itself into existing practice. The library can now respond with targeted learning activities informed by the RSD framework and embed these in curricula.

Strategies for building staff capacity through RSD workshops and conversations among educators using the RSD framework have successfully transferred the RSD into academic practices for:

- Mapping research skills and autonomy levels in assessments, units, and coursework majors to improve alignment with curricula

- Developing marking rubrics that make research skills explicit in assessment

- Embedding targeted skill-development programs in the curriculum to facilitate student success

- Establishing curriculum review and renewal and accreditation processes

- Hosting professional-development workshops on RSD applications for faculty and library staff

- Informing student research and learning consultations at the library

- Informing data-collection methods so that conversations with faculty to improve assessment design are based on evidence

- Designing reflective skill-development surveys for students

\section{Evaluating the Effectiveness of RSD Implementation}

Data gathered through survey instruments on the impact of the RSD on the curriculum indicate increases in embedded skill-development programs, improvements to assessment design, growth in use of RSD-informed marking rubrics, and increased library-faculty engagement in curriculum review and design.

Figure 2 shows that the number of RSD-informed, library-taught, skill-development programs for undergraduates increased by 25 percent between 2014 and 2015 (from 391 teaching programs in 2014, to 521 in 2015). Not all of these programs are embedded within a curriculum; however, library-taught skill development embedded within faculty curricula through the RSD CoP model increased by approximately one third in one year (from 252 RSD-embedded teaching programs in 2014 to 371 in 2015). Further, there has been increased interest in assessment of research skills articulated by the framework in undergraduate curricula. In 2014, only 16 percent (61) of undergraduate curriculum-embedded, library-teaching programs included assessment of research skills using RSD-informed marking rubrics. In 2015 this increased to 22.5 percent (117) of total programs. 
Figure 2. Growth in Library-Taught RSD Implementation Across Undergraduate Curricula

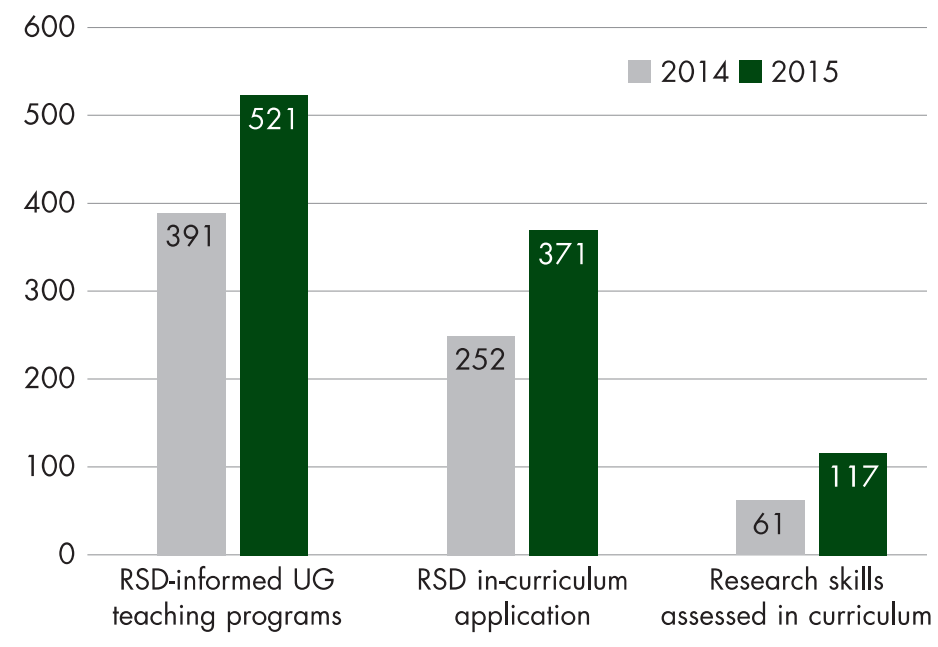

Regarding curriculum enhancement, the RSD CoP model has had substantial impact. Of the 623 RSD CoP collaborations embedding development of research skills within curricula from 2014 through 2015, 24.1 percent of these resulted in changes to core content to include skill development; 13.7 percent resulted in changes in assessment to more clearly articulate or assess the associated research skills; and 1.4 percent have resulted in adjustments to learning outcomes to make development of research skills explicit.

Not all RSD CoP library-faculty collaborations result in library-taught programs. The library has collaborated with faculty on a further 151 RSD-informed curriculum innovation projects resulting in curricular change being implemented by faculty. The results of these partnerships have also been captured in survey instruments and include: improvements to assessment design; amendments to assessment criteria to more explicitly assess research skills; adjustments to planned curricula to include embedded skill-development activities; and adjustments to more clearly express research skills within intended learning outcomes (Figure 3). In some instances a combination of these enhancements was made, so that the total number of changes to curricula (181) are greater than the total number of curriculum review projects (151).

While quantitative evidence demonstrates increased implementation of the RSD framework to explicitly state, develop, and assess research skills within Monash curricula, it fails to describe how this is achieved in practice using the RSD CoP model of engagement. Pretorius, Bailey and Miles (2013) and Taib and Holden (2013) have published detailed cases, respectively, of the practical application of the RSD framework
Figure 3. Library-Faculty RSD CoP Collaborations on Faculty Curriculum-innovation Projects (2014-2015)

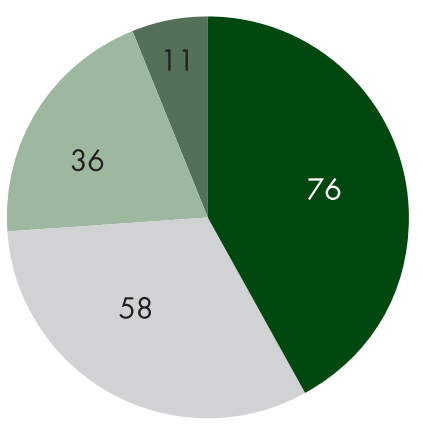

Assessment design $\square$ Assessment criteria

- Teaching and learning content Learning outcomes

in a single nursing course, and more broadly across an entire first-year undergraduate business-school curriculum.

The following three case studies highlight the Monash library-faculty engagement model, benefits to faculty curricula, and outcomes for student research skills not captured in the quantitative statistics already discussed. Case Study 1 demonstrates one such course enhancement currently underway in the Department of Arts, which is significant in that the RSD is being used as a tool to map research skills across several majors within an entire, complex program. Case Studies 2 and 3 represent examples in which library staff were invited to participate in curriculum review for specific courses and undertook to embed targeted development of research skills relevant to a particular discipline and identified needs of students.

\section{Case Study 1. RSD Mapping of Research Skills across a Program}

The Department of Arts is undergoing "unit enhancement," which involves redesign of disciplinary structure, curricula, assessment, and pedagogy. Through conversations with academic staff and through pooling library-team expertise, the RSD framework provides a means to appraise and articulate research skills within the curricula. The RSD is a powerful tool revealing where students' expected discipline-specific research skills did not match what students were currently taught within the curriculum, due to insufficient learning activities or assessments to scaffold incremental development of research skills.

For instance, first-year students need explicit scaffolding to develop new research skills, such as guiding questions to provoke critical thinking or a checklist to guide students in determining the academic credibility of resources (RSD au- 
tonomy level 1 or 2). Yet students may be assigned an assessment task designed as an open inquiry before students have learned the skills to operate with reduced or no stated limits, methodologies, structure, or scaffolding to guide their inquiry (RSD autonomy levels 3 and 4).

Course mapping also revealed that some skills were entirely overlooked within a first-year program. Recommendations were provided for where and how such skills can be developed. This may involve formulating assessment tasks or targeted learning-and-teaching resources to develop the requisite skills, and redesigning marking rubrics to explicitly evaluate research skills along with knowledge of the discipline. The RSD facilitates important dialogue between library and academic staff for students' research skill development while illustrating the library's contribution to the university's learning, teaching, and research aspirations.

\section{Case Study 2. Creating a Research-planning Tool in Industrial Design}

A third-year industrial design course requires students to integrate their knowledge of industrial design through holistically designed project work, to demonstrate their professional competence. Introducing students to the RSD framework, including the introduction of a "research planner," was key to students' understanding that the research process involved development of a series of skills, rather than a mechanical approach to finding information. The stages of research were visually represented by the RSD facets arranged in a circular flow chart to reinforce the iterative nature of the research process.

The research planner, a systematic template articulating facets of the RSD, scaffolded and prompted students throughout the research process. It was reinforced by drawing students' attention to the research process at each stage of the class. Implementation of the framework has received positive feedback from students and unit coordinators, with measurable improvements noted in the depth of research and quality of projects. Commented Rowan Page, lead faculty member for this course: "The research-skills development sessions allowed the students a concise and structured introduction to research, allowing them to practice and learn skills that were immediately translated into their studio based projects, focusing and lifting the quality of their research inquiry."

\section{Case Study 3. RSD-informed Changes Enhance a Core Management Curriculum}

The library developed a large RSD CoP in a core first-year undergraduate management course with a lead academic and eleven tutors. The faculty member had two main objectives: 1) to develop and assess research skills and prepare the large (600+) student cohort for more rigorous research assess- ment in later years, and 2) to reduce the extensive need for cross-marking by the lead academic where tutors had variable expectations. A librarian, learning skills adviser, and the lead academic used the RSD to determine and describe the research skills first-year students need to pass (earning 50-59 percent for an overall final result); to pass with a credit (6069 percent); to pass with distinction (70-79 percent), and to pass with a high distinction (80 percent or more).

These descriptions were adapted to create assessment rubrics that described the varying levels of skills required for each faculty assessment task within the course. Assessment rubrics were shared with the wider teaching team for discussion and editing to ensure a clear and uniform interpretation of assessment criteria and achievement levels. Assessment tasks were consequently revised to ensure that the language used within assessment rubrics was integrated seamlessly into task descriptions, so that it was explicit to students that research skills were valued and would be assessed. A range of skill development activities were then co-developed for tutorials or provided in parallel with the curriculum in faceto-face and online formats, to ensure adequate opportunities for students to develop their research skills.

The results of this collaboration were astounding. The lead faculty member reported an overall higher assignment standard, with final assignment results (typically a bell curve) skewed toward the distinction level, and fewer students failing. The span of students' grades was 2 percent failed, 5 percent passed, 26 percent received credit, 55 percent passed with distinction, and 12 percent passed with high distinction. The lead faculty member also reported reduced need for marking moderation due to the clarity in RSD-informed assessment criteria and levels of achievement.

The RSD CoP has created a growing movement at Monash toward developing and assessing research skills throughout the curriculum. In a higher education landscape featuring an increasing focus on engaging undergraduates in research (Wilson, Howitt and Higgins 2015), explicitly stating, teaching, and assessing research skills makes sense. Healey states that "one of the most effective ways in which students may benefit from research ... is through active engagement in the research process" $(2005,196)$. Yet Wilson, Howitt, and Higgins (2015) have identified a significant misalignment between the intended learning achieved through a practical research experience and conventional assessment practices. As they explain, assessment focused on a final outcome such as a report or presentation "implies that successful learning in a research project is best measured by the results obtained, rather than the thinking processes and understanding developed in obtaining them" (Wilson, Howitt and Higgins 2015, $5)$. 
Transformation in the Monash University curriculum as a result of the RSD community of practice gives students throughout their undergraduate journey a discipline-specific research process and outlines associated research skills required for any assessment task, and for future postgraduate research experiences. As Willison (forthcoming) states, "A model that embeds research skill development in the curriculum is of particular interest because it has the potential to be more efficient, more equitable and broader-reaching than mentored undergraduate research models."

\section{Overcoming Challenges}

Traditional interpretations of information literacy in the context of preparing students for research have presented a significant barrier to initial library-faculty engagement. However, implementation of the RSD CoP and gradual dissemination of the RSD framework through a library-led grassroots strategy has established a broader understanding of information literacy in the context of developing students' research skills. As familiarity with the RSD framework increases at Monash, the library can refer to the framework to demystify how librarians and learning-skills advisers can, with faculty, collaboratively develop research skills within a curriculum. The collaborative application of the RSD framework is overcoming initial barriers, building trust and confidence between educators, and clarifying the library's educational role and contribution to student learning (Torres et al. 2011, 2012).

Another challenge has been how to overcome first impressions of the RSD as a seemingly complex, restrictive, and impenetrable framework, as well as the interpretation by some that the RSD is a new curriculum in itself. To overcome such perceptions, and to allow educators the opportunity to discover what the RSD means for their own practice, the RSD is taught conceptually through discovery pedagogies, allowing the flexibility and non-prescriptive nature of the RSD to emerge. Workshop activities are designed to reveal the potential of the RSD as a tool to inform and make skills for researching in different contexts explicit within existing or new curricula.

\section{Conclusion}

The recognized importance of the development of students' research skills as an integrated component of curriculum and assessment design signals a significant opportunity for academic libraries to reconceptualize their current contributions and approaches to this learning outcome. The experience at Monash University demonstrates the value of incorporating an RSD approach to overcome perceived limitations of the library's contributions to student learning and how this can be achieved. The RSD framework has enabled a reconceptualization and a more holistic interpretation of information literacy by representing the concept as a set of clearly articulated research skills undertaken as part of any research process and adaptable to a wide variety of disciplinary contexts.

In challenging times when organizations need to be agile and seek different ways to configure resources for maximum gain, Monash University library staff are enhancing and extending the breadth, depth, and impact of their contributions to student learning. Our professional partnerships model has established with faculty a community of practitioners who are learning and collaboratively applying the RSD framework. Importantly and distinctively, the implementation of the RSD framework as a single pedagogical tool has facilitated a shared response by educators to develop discipline-specific research skills in curricula that include different pedagogies. Thus has emerged a successful, sustainable, and collaborative model for library engagement in the curriculum to holistically develop undergraduate students' research skills.

\section{Acknowledgments}

The authors would like to acknowledge the contributions by Monash University Library staff members to this manuscript: Anna Davis, Sebastian Borutta, Jennifer Casey, Anne Holloway, Linda Kalejs, Janet McGary, Romany Manuell, and Fiona Patterson.

\section{References}

Bloom, Benjamin, Max D. Engelhardt, Edward J. Furst, Walker H. Hill, and David R Krathwohl. 1956. Taxonomy of Educational Objectives. New York, NY: David McKay Company.

Boud, David. 1988. Developing Student Autonomy in Learning. 2nd ed. London, UK: Kogan Press.

Bruce, Christine. 2001. "Faculty-Librarian Partnerships in Australian Higher Education: Critical Dimensions." RSR: Reference Services Review 29(2): 106-15. doi: 10.1108/00907320110394146.

Bundy, Alan. 2004. Australian and New Zealand Information Literacy Framework: Principles, Standards and Practice. Adelaide, Australia: Australia and New Zealand Institute for Information Literacy. Accessed November 15, 2015. http://www.caul.edu.au/content/upload/files/info-literacy/ InfoLiteracyFramework.pdf.

Chanock, Kate. 2007. "What Academic Language and Learning Advisers Bring to the Scholarship of Teaching and Learning: Problems and Possibilities for Dialogue with the Disciplines." Higher Education Research and Development 26(3): 269-280. doi: 0.1080/07294360701494294.

Chen, Kuan-nien, and Lin Pei-chun. 2011. "Information Literacy in University Library User Education." Aslib Proceedings 63(4): 399-418. doi: $10.1108 / 00012531111148967$.

Christiansen, Lars, Mindy Stombler, and Lyn Thaxton. 2004. "A Report on Librarian-Faculty Relations from a Sociological Perspective." The Journal of Academic Librarianship 30(2): 116-121. doi: 10.1016/j.acalib.2004.01.003.

Healey, Mick. 2005. "Linking Research and Teaching to Benefit Student Learning in Higher Education." Journal of Geography in Higher Education 29 (2): 183-201. doi: 10.1080/03098260500130387. 
Healey, Mick, and Alan Jenkins. 2009. Developing Undergraduate Research and Inquiry. York: Higher Education Academy. Accessed January 22, 2016. https:// www.heacademy.ac.uk/node/3146.

Hensley, Merinda K., Sarah L. Shreeves, and Stephanie Davis-Kahl. 2014. "A Survey of Library Support for Formal Undergraduate Research Programs." College \& Research Libraries 75(4): 422-441. doi: 10.5860/crl.75.4.422.

Ivey, Ruth. 2003. "Information Literacy: How do Librarians and Academics Work in Partnership to Deliver Effective Learning Programs?" Australian Academic \& Research Libraries 34(2): 100. doi: 10.1080/00048623.2003.10755225.

Jenkins, Alan, and Mick Healey. 2015. "International Perspectives on Strategies to Support Faculty Who Teach Students Via Research and Inquiry." CUR Quarterly 35(3): 31-37.

Kempcke, Ken. 2002. "The Art of War for Librarians: Academic Culture, Curriculum Reform, and Wisdom from Sun Tzu." Portal: Libraries and the Academy 2(4): 529-551. doi: 10.1353/pla.2002.0081.

Lave, Jean, and Etienne Wenger. 1991. Situated Learning: Legitimate Peripheral Participation. Cambridge England: Cambridge University Press.

McGuinness, Claire. 2006. "What Faculty Think-Exploring the Barriers to Information Literacy Development in Undergraduate Education." The Journal of Academic Librarianship 32(6): 573-582. doi: 10.1016/j.acalib.2006.06.002.

Monash University. Better Teaching Better Learning Agenda, Melbourne, 2013

Moselen, Chris, and Li Wang. 2014. "Integrating Information Literacy into Academic Curricula: A Professional Development Programme for Librarians at the University of Auckland." The Journal of Academic Librarianship 40(2): 116-123. doi: 10.1016/j.acalib.2014.02.002.

Pretorius, Lynette, Carolyn Bailey, and Maureen Miles. 2013. “Constructive Alignment and the Research Skills Development Framework: Using Theory to Practically Align Graduate Attributes, Learning Experiences, and Assessment Tasks in undergraduate Midwifery." International Journal of Teaching and Learning in Higher Education 25(3): 378-387.

Schrage, Michael. 1990. Shared Minds. New York, NY: Random House.

Smith, Lisa. 2011. "Monash University Library: A New Paradigm for a New Age." Australian Academic and Research Libraries 42(3): 246-264. doi: 10.1080/00048623.2011.10722235.

Stamatoplos, Anthony. 2009. "The Role of Academic Libraries in Mentored Undergraduate Research: A Model of Engagement in the Academic Community." College \& Research Libraries. May 70(3): 235-249. doi:10.5860/ crl.70.3.235.

Taib, Anne, and Julie Holden. 2013. "'Third generation' Conversations - A Partnership Approach to Embedding Research and Learning Skills Development in the First Year. A Practice Report." The International Journal of the First Year in Higher Education 4(2): 131. doi: 10.5204/intjfyhe.v4i2.178.

Torres, Lynette, Leanne McCann, Glen Croy, Susan Mayson, and Jan Schapper. 2011. Collaborative Collisions: Learning Skills, Information Literacy and Disciplines. Poster presented at the HERDSA (Higher Education Research Development Association), Gold Coast, Queensland, Australia, July, 2011.

Torres, Lynette, Leanne McCann, Glen Croy, and Susan Mayson. 2012. Bridging the Divide: Generating Dynamic University Wide Library-Faculty Connections to Enable the Explicit Development of Students' Research Skills. Presented at the Higher Education Research and Development Society of Australasia (HERDSA), International Conference, Hobart, Australia, July 3-7, 2012.
Weetman, Jacqui. 2005. "Osmosis-Does It Work for the Development of Information Literacy?" The Journal of Academic Librarianship 31(5): 456-460. doi: 10.1016/j.acalib.2005.05.007.

Wenger, Etienne. 1988. Communities of Practice: Learning, Meaning, and Identity. Cambridge, U.K.: Cambridge University Press.

Wijayasundara, Nayana. 2008. "Faculty-Library Collaboration: A Model for the University of Colombo." The International Information \& Library Review 40: 188-198. doi: 10.1016/j.iilr.2008.06.04.

Willison, John, and Kerry O'Regan. 2007. “Commonly Known, Commonly Not Known, Totally Unknown: A Framework For Students Becoming Researchers." Higher Education Research \& Development 26(4): 393-409.

Willison, John, and Kerry O'Regan. 2006/2013. "Research Skill Development Framework." http://www.adelaide.edu.au/rsd/ Accessed September 15, 2015.

Willison, John, and Femke Buisman-Pijlman. 2016. "PhD Prepared: Research Skill Development Across Undergraduate Years." International Journal for Researcher Development 17(1): 63-83. doi: 10.1108/IJRD-07-2015-0018.

Willison, John, Fizza Sabir, and Judith Thomas. "Shifting Dimensions of Autonomy in Students' Research and Employment." Higher Education Research \& Development, forthcoming.

Wilson, Anna, Susan Howitt, and Denise Higgins. 2015. "A Fundamental Misalignment: Intended Learning and Assessment Practices in Undergraduate Science Research Projects." Assessment and Evaluation in Higher Education. Volume Online Early Version: 1-16. doi: 10.1080/02602938.2015.1048505.

\section{Lynette Torres}

Monash University, lynette.torres@monash.edu

Lynette Torres, information research skills manager, has extensive experience designing and developing innovative learning approaches for development of students' research skills. She formulated and led the Monash University library's implementation of the Research Skill Development (RSD) framework to catalyze library-faculty partnerships for the development of students' research skills in coursework. She is active in the educational research community and has co-facilitated RSD workshops nationally and internationally. Her work has contributed to the invigoration of the skills agenda at Monash University, influencing university policy endorsement of the RSD. Torres has received three Monash University Learning and Teaching awards and received the CAUL (Council of Australian University Librarians) Achievement Award in 2014.

Sarah Jansen is the learning skills manager at Monash University Library, with qualifications in biomedical sciences and a PhD based in embryology. Jansen has 10 years of experience in research and teaching in higher education, as well as experience in course coordination and curriculum design. She has particular interests in blended-learning techniques to enhance student engagement, learning-oriented assessment practices, and educational approaches to academic integrity.

\section{doi: $10.18833 / \operatorname{curq} / 37 / 1 / 9$}

